\title{
ANÁLISE MICROCLIMATICA DAS UNIDADES DE PAISAGEM DA LAGOA SALINA DO RONDOM, FAZENDA FIRME - PANTANAL DA NHÊCOLANDIA, MS.
}

\author{
Heloissa Gabriela Silva Sokolowski ${ }^{1}$
}

\author{
Glauber Stefan Barbosa ${ }^{2}$
}

\section{Arnaldo Yoso Sakamoto ${ }^{3}$}

RESUMO: O trabalho visa analisar a dinâmica microclimática das unidades geomorfológicas distintas da área da Fazenda Firme, na sub-região do Pantanal da Nhecolândia, em especial, a dinâmica climática da Lagoa Salina do Rondom. Foram realizados um conjunto de observações meteorológicas num transecto abrangendo a praia da lagoa salina, área de transição (praia e gramínea), área de mata (vegetação esparsa) e cordilheira (mata densa), por meio de um conjunto de abrigos experimentais meteorológicos com um sensor de temperatura denominado Datalogger mod. HT-500 (Temperatura e Umidade Relativa), estendendo-se no sentido N/S. Os dados foram captados automaticamente pelo sensor, associados a cobertura vegetal de cada unidade geomorfológica registrando a ocorrência das variações climáticas programadas a cada $3 \mathrm{~h}$ no dia 6 de Fevereiro de 2013. Os estudos realizados mostraram a importância de se classificar e coletar dados em transeção, associados a ocupação do solo, têm interferência na variação climática dos ambientes.

1 Acadêmica do curso de Geografia pela Universidade Federal de Mato Grosso do Sul - geo.sokolowski@gmail.com

2 Acadêmica do curso pós-graduação em Geografia pela Universidade federal de Mato Grosso do Sul- andressagponso@gmail.com

3 Professor do curso de Geografia da Universidade Federal de Mato Grosso do Sul - arnaldosakamoto@gmail.com. 
Palavras-chave: Variações climáticas. Temperatura. Paisagem

\section{INTRODUÇÃO}

O Pantanal é uma extensa área que apresenta uma organização complexa constituída de lagoas (doces e salinas), cordilheiras (cordões arenosos alongados), intercalados por vazantes, corixos, que espraiam suas águas na planície durante o período da cheia, apresenta também, uma riqueza de flora e fauna, com a presença do homem, associadas às condições naturais como a sua dinâmica hídrica e climática.

O clima do Pantanal é tropical, com duas estações bem definidas, verão chuvoso e inverno seco. Apresenta uma pluviosidade média anual em torno de $1.000 \mathrm{~mm}$, temperatura média anual entre $24^{\circ} \mathrm{C}$ e $25^{\circ} \mathrm{C}$ e evapotranspiração anual superior a $1.140 \mathrm{~mm}$ (ALFONSI E CAMARGO, 1986; ZAVATINI, 1990).

Silva e Sakamoto $(2002 ; 2003)$ e Silva (2003) estudaram o micro clima em diferentes regiões do Pantanal da Nhecolândia e do Miranda. Os resultados indicaram que há comportamento térmico semelhante entre os ambientes das praias salinas, das baías e banhados, pois apresentaram maior amplitude térmica e temperaturas mais elevadas, enquanto nas cordilheiras as temperaturas variaram menos e eram inferiores. Em área construída, as temperaturas eram mais elevadas. No outono, com baixa nebulosidade e pouco vento, a temperatura do solo na praia da salina chegou a apresentar diferença de até $6^{\circ} \mathrm{C}$ em relação à temperatura do solo da cordilheira. As cordilheiras apresentaram umidade relativa do ar mais elevada.

A área da lagoa salina estudada está localizada na sub-região do Pantanal da Nhecolândia/MS, entre os paralelos de $19^{\circ} 04^{\prime} 33^{\prime \prime}$ S e $19^{\circ} 21^{\prime} 00^{\prime \prime} \mathrm{S}$, e meridianos de $56^{\circ}$ $53^{\prime} 20^{\prime \prime} \mathrm{W}$ e $57^{\circ} 05^{\prime} 23^{\prime \prime} \mathrm{W}$ é denominada Fazenda Firme. Esta fazenda particulariza-se por apresentar de modo muito representativo o grande complexo paisagístico existente no Pantanal da Nhecolândia, apresentando baías, lagoas salinas, cordilheiras, vazantes, áreas de campo com gramíneas nativas e também pastagens introduzidas. Trata-se de uma área de transição entre as áreas de inundação do rio Paraguai, do rio Negro, da vazante do Corixão e da planície flúvio-lacustre do Pantanal da Nhecolândia. 
Este estudo tem como objetivo geral contribuir para o conhecimento microclimático em diferentes unidades de geomorfológicas da área da Fazenda Firme, Pantanal da Nhecolândia MS. Os objetivos específicos foram: (1) entender as diferentes temperaturas em uma transeção abrangendo as unidades geomorfológicas da Lagoa Salina. (2) analisar os fatores que propiciam o micro-clima desta área, e (3) estudar a influência da ocupação do solo no micro-clima local.

\section{MATERIAIS E MÉTODOS}

Para a realização do trabalho de pesquisa torna-se indispensável à definição do método que venha viabilizar a execução da mesma, uma vez que esse tem como finalidade dar ordem a pesquisa, e indicar os meios de investigação da mesma. Primeiramente foram efetuam levantamentos bibliográficos em gabinete, com cunho conceitual e teórico (dando ênfase aos conceitos de clima, micro-clima, solo, vegetação e paisagem, bem como vistas no objetivo do estudo.

A metodologia utilizada baseou-se na proposta de Sezerino e Monteiro (1990), procurando caracterizar a variação térmica nas unidades da paisagem selecionadas ao longo de um transecto e realizando-se as medidas de temperatura do ar (a 1,5 m) e da umidade relativa do ar (SEZERINO \& MONTEIRO, 1990).

Com o objetivo de dar continuidade às investigações microclimáticas no Pantanal da Nhecolândia, foram realizadas medidas e observações de campo em área da lagoa salina durante o período de "cheia". O experimento foi realizado no dia 06 Fevereiro de 2013, o trabalho de campo foi desenvolvido nas proximidades da Lagoa Salina do "Rondom", área pertencente à Fazenda Firme, através de uma transeção de 30,7 m abrangendo a Praia da Lagoa; área de transição (praia/ mata), área de mata (intermediário) em terreno pouco mais elevado que a praia e coberto por carandás e Cordilheira (mata densa).

Foram utilizados nos levantamentos de campo 4 abrigos meteorológicos construídos de madeira compensado de paredes duplas, de cor branca, com furos que permitissem a circulação do ar no interior do abrigo. Foram instalados a 1,5m de altura do solo fixados a uma base, enterrados no solo para que não caíssem com possíveis ventos. No interior de cada abrigo foram instalados sensores Datalogger mod. HT-500 
(Temperatura e Umidade Relativa) e as medidas foram registradas automaticamente de 3 em 3 horas durante 24h do dia 06 de Fevereiro de 2013.

Os dados foram analisados e organizados em gráficos. A circulação da atmosfera no período dos experimentos foi realizada através da leitura de cartas sinóticas da Marinha do Brasil, apoiados em imagens do satélite meteorológico GOES 12 (Infravermelho) dos dias das análises, obtidas junto ao site oficial do Instituto Nacional de Pesquisas Espaciais - CPTEC/ INPE e para localização geográfica foi utilizado GPS de navegação Garmim.

Foram realizados levantamentos foto-descritivos (máquina fotográfica), para caracterização dessas unidades da paisagem. Os registros foram organizados em tabelas e gráficos das informações coletadas juntamente com um perfil topográfico da área de estudo explicitando o tipo de vegetação de cada compartimento.

\section{RESULTADOS}

O experimento foi realizado em condições de tempo não muito favoráveis, pois neste período do ano há um aumento na freqüência de ocorrências de nebulosidade e chuva, dessa forma, as leituras dos aparelhos iniciaram com a presença de um sistema de baixa pressão atmosférica, provocada pelo forte aquecimento da área central do continente, que formam áreas de instabilidades tropicais. Este sistema de tempo é conhecido pelos meteorologistas por Baixa do Chaco.

Monteiro (1951) estudando o clima na antiga Região Centro-Oeste analisou o clima pantaneiro e utilizou como base os dados da estação meteorológica de Corumbá/MS, onde as temperaturas da média anual são de $24,9^{\circ} \mathrm{C}$, com temperaturas máximas em dezembro e fevereiro entre $27,2^{\circ} \mathrm{C}$ e $27,7^{\circ} \mathrm{C}$. A estação chuvosa inicia-se em novembro e a seca inicia-se em maio. A pressão no período da seca se eleva e as temperaturas baixam com média de $21^{\circ} \mathrm{C}$ em julho, a umidade cai, registrando em agosto $61 \%$. (Gradella 2005 Apud Monteiro 1951).

No transeto foram escolhidos quatro pontos para realizar as medidas: na praia da lagoa (abrigo1); na área de transição (praia/gramínea/ mata) (abrigo2), área de mata (intermediário/mata esparsa) (abrigo3) e a cordilheira (mata densa) (abrigo 4) ( Figura 1). 
Nos registros realizados no intervalo das $7 \mathrm{~h} 23$, a variação de temperatura foi de $6,9^{\circ} \mathrm{C}$ entre o abrigo 1,2 e 4, sendo a maior temperatura abrigo 1 registrando $31,9^{\circ} \mathrm{C}$ e a menor no interior da cordilheira, registrando $25^{\circ} \mathrm{C}$. A umidade relativa do ar não apresentou diferenças acentuadas entre os ambientes, registrando no abrigo 3 e 4 maior umidade relativa do ar na área de mata esparsa (abrigo 3) e de mata densa (abrigo 4). (Tabela 1).

Tabela 1: Medidas de temperatura do ar e Umidade Relativa - 7h23 - 06/02/2013

\begin{tabular}{c|l|c|c}
\hline Abrigo & \multicolumn{1}{|c|}{ Localidade } & Temperatura( ${ }^{\circ} \mathbf{C}$ ) & Umidade relativa (\%) \\
\hline 01 & Lagoa Salina (Praia) & 31,9 & 73,5 \\
\hline 02 & Área de transição & 30,8 & 75,8 \\
\hline 03 & Mata & 30,5 & 78,6 \\
\hline 04 & Cordilheira & 25 & 88,3 \\
\hline
\end{tabular}

Org. SOKOLOWSKI.

Nos registros do transeto no intervalo das 10h23, a variação da temperatura do ar foi de $2^{\circ} \mathrm{C}$. A maior temperatura registrada nesse período foi no abrigo 1 com $35,1^{\circ} \mathrm{C}$; e a menor temperatura registrada foi no abrigo $4 \mathrm{com} 33,1^{\circ} \mathrm{C}$. Nos demais pontos não houveram diferenças significativas. A umidade relativa do ar apresentou variação maior entre a área da praia (abrigo 1) e cordilheira de mata densa (abrigo 4) (Tabela 2).

Tabela 2: Medidas de temperatura do ar e Umidade Relativa - 10h23 - 06/02/2013

\begin{tabular}{c|l|c|c}
\hline Abrigo & \multicolumn{1}{|c|}{ Localidade } & Temperatura $\left({ }^{\circ} \mathbf{C}\right)$ & Umidade relativa (\%) \\
\hline 01 & Lagoa Salina (Praia) & 35,1 & 61,4 \\
\hline 02 & Área de transição & 34,9 & 62,3 \\
\hline 03 & Mata & 34,8 & 62,2 \\
\hline 04 & Cordilheira & 33,1 & 70,9 \\
\hline
\end{tabular}

Org. SOKOLOWSKI.

Nos registros do transeto no intervalo das 13h23, o abrigo 1 e 2 recebiam insolação direta enquanto no abrigo 4 a cobertura vegetal impedia a penetração da insolação. Neste período do dia as temperaturas do ar apresentaram variação de temperatura de 3,4º entre o abrigo 1 e o abrigo 4. Nos demais pontos houve oscilação de temperatura pouco 
significativa entre os abrigos 1 e 2 de $0,3^{\circ} \mathrm{C}$, e de $2,2^{\circ} \mathrm{C}$, entre os abrigos 3 e 4 . A umidade relativa do ar apresentou mais elevada na cordilheira com 66,8\% (Tabela 3).

Tabela 3: Medidas de temperatura do ar e Umidade Relativa - 13h23 - 06/02/2013

\begin{tabular}{c|l|c|c}
\hline Abrigo & \multicolumn{1}{|c|}{ Localidade } & Temperatura $\left({ }^{\circ} \mathbf{C}\right)$ & Umidade relativa (\%) \\
\hline 01 & Lagoa Salina (Praia) & 36,7 & 54,5 \\
\hline 02 & Área de transição & 36,4 & 51,8 \\
\hline 03 & Mata & 35,5 & 58,3 \\
\hline 04 & Cordilheira & 33,3 & 66,8 \\
\hline
\end{tabular}

Org. SOKOLOWSKI.

Nos registros do transeto no intervalo das 16h23, a variação da temperatura foi de $1,1^{\circ} \mathrm{C}$ entre o abrigo 1 e o abrigo 4. Segundo os registros realizados, houve pouca altercação nas temperaturas registradas nos demais pontos. Em todos os ambientes foram registrados aumento de umidade relativa do ar, provavelmente pela evaporação da água da lagoa e da brisa. (Tabela 4).

Tabela 4: Medidas de temperatura do ar e Umidade Relativa - 16h23 - 06/02/2013

\begin{tabular}{c|l|c|c}
\hline Abrigo & \multicolumn{1}{|c|}{ Localidade } & Temperatura $\left({ }^{\circ} \mathbf{C}\right)$ & Umidade relativa (\%) \\
\hline 01 & Lagoa Salina (Praia) & 27,8 & 69,8 \\
\hline 02 & Área de transição & 27,3 & 73,1 \\
\hline 03 & Mata & 27,7 & 66,6 \\
\hline 04 & Cordilheira & 26,7 & 72 \\
\hline
\end{tabular}

Org. SOKOLOWSKI.

Nos registros do transeto no intervalo das 19h23, a variação da temperatura foi de $0,9^{\circ} \mathrm{C}$ entre o abrigo 1 e o abrigo 4. A maior temperatura registrada nesse período foi no abrigo 1 com $25,8^{\circ} \mathrm{C}$; e a menor temperatura registrada foi no abrigo 4 com $24,9^{\circ} \mathrm{C}$. Nos demais pontos a variação de temperatura deu-se entre $0,1^{\circ} \mathrm{C}$ e $0,4^{\circ} \mathrm{C}$. A umidade relativa do ar apresentou valores semelhantes em todos os ambientes, mantende-os relativamente úmidos (Tabela 5 ). 
Tabela 5: Medidas de temperatura do ar e Umidade Relativa - 19h23 - 06/02/2013

\begin{tabular}{c|l|c|c}
\hline Abrigo & \multicolumn{1}{|c|}{ Localidade } & Temperatura $\left({ }^{\circ} \mathbf{C}\right)$ & Umidade relativa (\%) \\
\hline 01 & Lagoa Salina (Praia) & 25,8 & 81,7 \\
\hline 02 & Área de transição & 25,2 & 82,7 \\
\hline 03 & Mata & 25,6 & 80 \\
\hline 04 & Cordilheira & 24,9 & 82,3 \\
\hline
\end{tabular}

Org. SOKOLOWSKI.

Nos registros do transeto no intervalo das $22 \mathrm{~h} 23$, a variação da temperatura foi de $0,8^{\circ} \mathrm{C}$ entre $\circ$ abrigo 1 e o abrigo 4 . A maior temperatura registrada nesse período foi no abrigo $1 \mathrm{com} 26,2^{\circ} \mathrm{C}$; e a menor temperatura registrada foi no abrigo $4 \mathrm{com} 25,8^{\circ} \mathrm{C}$. Entre os abrigos 1 e 2 houve queda de temperatura de $0,4^{\circ} \mathrm{C}$; entre os abrigos 2 e 3 houve aumento de $0,3^{\circ} \mathrm{C}$, no abrigo 4 cai a temperatura em $0,7^{\circ} \mathrm{C}$ em relação aos demais abrigos. Não houve muita variação na umidade do ar entre o período das $19 \mathrm{~h} 23$ para o período das $22 \mathrm{~h} 23$ mantendo um media de $86,2 \%$ (Tabela 6).

\begin{tabular}{c|l|c|c}
\multicolumn{3}{c}{ Tabela 6: Medidas de temperatura do ar e Umidade Relativa $-22 \mathrm{~h} 23-06 / 02 / 2013$} \\
\hline Abrigo & \multicolumn{1}{|c}{ Localidade } & Temperatura $\left({ }^{\circ} \mathbf{C}\right)$ & Umidade relativa (\%) \\
\hline 01 & Lagoa Salina (Praia) & 26,2 & 86,3 \\
\hline 02 & Área de transição & 25,8 & 87,4 \\
\hline 03 & Mata & 26,1 & 84,7 \\
\hline 04 & Cordilheira & 25,4 & 86,7 \\
\hline
\end{tabular}

Org. SOKOLOWSKI

Os dados supracitados podem ser melhores observados na figura abaixo: 

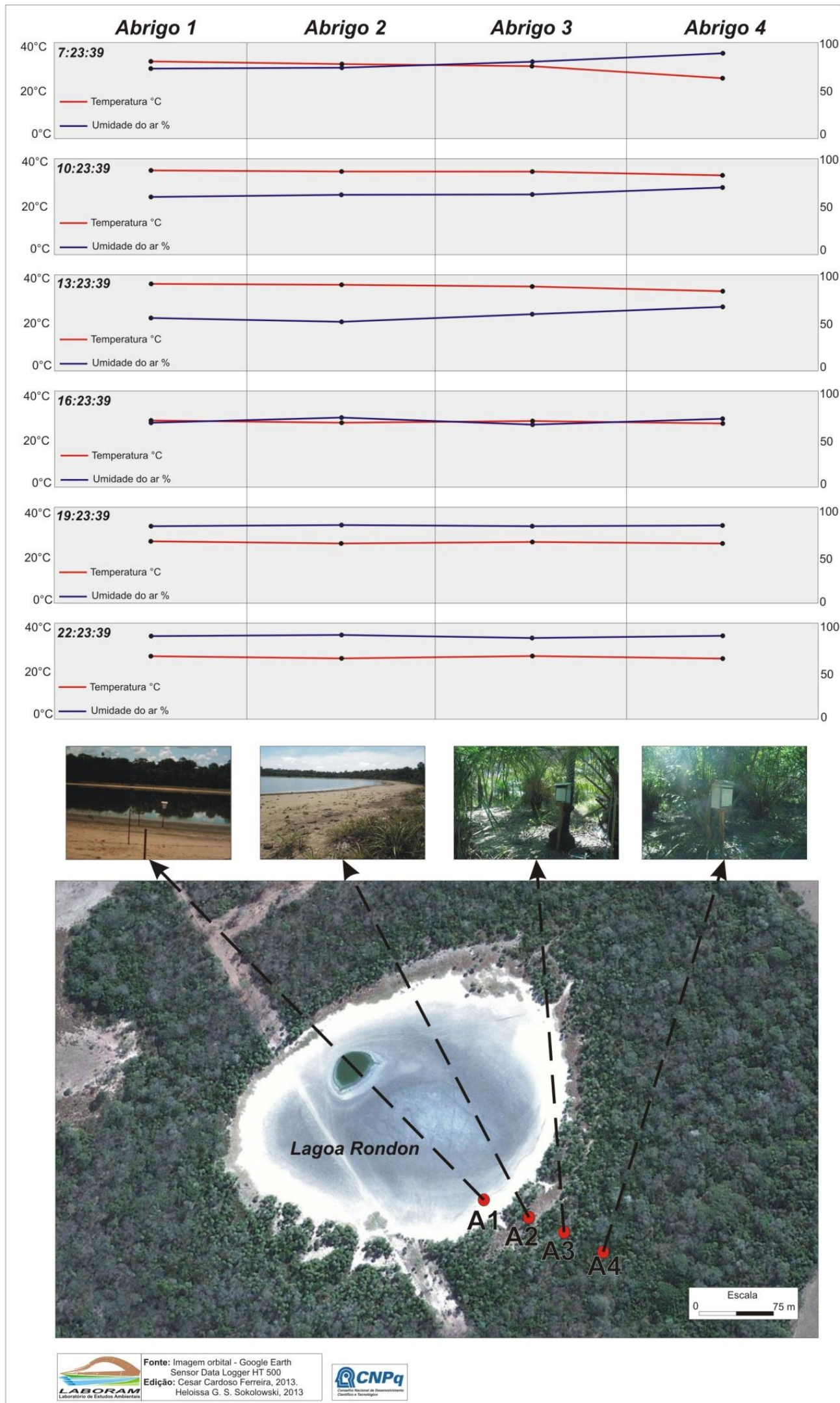

Figura 1: Croqui representativo do transecto 


\section{Discussão dos resultados}

Conforme Ross, 1992, as Unidades de Paisagens se individualizam pelo relevo, clima, cobertura vegetal, solos ou até mesmo pelo arranjo estrutural e o tipo de litologia ou exclusivamente por um desses elementos (ROSS,1992). As Unidades de Paisagem apresentam fronteiras de complexa delimitação (já que têm um espectro taxonômico variado), que ocupam um determinado espaço e certo período de tempo, cuja existência é condicionada pelo funcionamento de seus elementos (MONTEIRO, 2000).

Assim, podemos considerar a vegetação, água e a ocupação do solo da área estudada como um fator de relevância no micro clima local. De tal modo, buscamos evidenciar os possíveis fenômenos que influenciam diretamente os elementos climáticos provocando uma nítida alteração sobre as unidades analisadas.

Podemos considerar que a área de praia da Lagoa (Abrigo 1), apresenta características climáticas mais acentuadas, pois é um ambiente que não habita indivíduos vegetais. A maior temperatura na praia da lagoa salina se dá pelo fato de não haver cobertura vegetal e a radiação solar ser direta no solo arenoso da praia. Uma área sem cobertura vegetal torna-se profundamente vulnerável a oscilação, com um micro clima instável, visto que a ausência de vegetação propicia uma alteração de gradiente bem visível, sobretudo na temperatura e evaporação, observando que a evaporação na área sem vegetação é superior a da área de mata, devido principalmente à incidência direta dos raios solares, sobretudo ao meio dia quando o Sol atinge o seu zênite, o que aumenta a capacidade de evaporação.

$\mathrm{Na}$ área de transição (praia/ cordilheira) (Abrigo 2), apresenta características climáticas moderadas, é considerada um ambiente intermediário, na medida em que habita poucos indivíduos vegetais. Essa área contém características geomorfológicas similares a uma pequena elevação em direção a mata, o que faz que a dinâmica climática não seja acentuada.

$\mathrm{Na}$ área de mata (intermediário) (Abrigo 3), podemos classificá-la como ambiente climático com variação moderada, o ambiente é caracterizado por apresentar vegetação esparsa, possibilitando a penetração dos raios solares em vários momentos do dia.

No interior Cordilheira (Abrigo 4) as características climáticas têm variações evidentes ao decorrer do dia. A temperatura mais amena na cordilheira se dá por um 
processo inverso do da praia da salina, a densa cobertura vegetal arbórea impede a penetração dos raios solares e conseqüentemente seu alto aquecimento. Assim, podemos considerar a serrapilheira como sendo um componente que apresenta boas condições de calor específico, constatamos ainda a possibilidade que a mesma desempenha um importante papel na manutenção do ritmo da temperatura no interior de uma Cordilheira (Mata). Tendo em vista que esta durante boa parte do dia encontra-se com uma temperatura baixa e ao entardecer mantém-se alta, o que implica dizer que possivelmente no período noturno a mesma torna-se mais elevada, de modo a contribuir para que a mata não perca seu calor, diferente das outras unidades que pedem sua energia mais rapidamente.

\section{CONSIDERAÇÃO FINAIS}

Através da verificação preliminar dos registros coletados em campo, constatamos que há diferença climática nas unidades geomorfológicas, em função de suas características distintas. A diferença microclimática não apresentou resultado muito acentuado, porém, quando levamos em consideração a proximidade e o tamanho das unidades, verificamos que os resultados apresentaram uma oscilação considerável. O clima registrado em cada ambiente possibilitou estabelecer que os elementos das unidades da paisagem e a ocupação podem ser condições que alteram o clima da diferentes unidades.

Podemos considerar que a área da Cordilheira ou ambientes que apresentam vegetação densa, é um fator importante na alteração na dinâmica do clima de cada local, em um ambiente de floresta ou mesmo aqueles mais arborizados é perceptível a variação de alguns elementos microclimáticos, como a diminuição da temperatura, aumento da umidade relativa do ar.

Nos ambientes intermediários as características climáticas apresentam-se moderadas, na medida em que as características desse ambiente se sobressaíam (solo exposto, vegetação), considerada como fator climático e que atua mais diretamente sobre os elementos climáticos nessa escala, diminuição da vegetação trazendo conseqüências como maior variação dos elementos climáticos, exposição do solo aos efeitos de radiação solar direta, eólicos, dentre outros. 


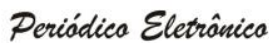

Já o ambiente aberto (área de praia da Lagoa), isto é, que não dispõe de cobertura vegetal, apresentou grande variação entre seus diversos elementos climáticos, podendo ser considerado um ambiente instável e com forte tendência a esse fenômeno, uma vez que a instabilidade microclimática pode atribuir a importância da cobertura vegetal como um agente significante do clima e fator importante como elemento de conservação da umidade.

Além disso, a metodologia empregada neste estudo poderá permitir a outros pesquisadores a aplicação em qualquer outra situação climática, ou em outra região que apresente áreas distintas quanto à cobertura vegetal, permitindo a obtenção de resultados semelhantes, pois acreditamos que as conclusões serão de elevada similaridade e que a alteração da cobertura vegetal pode implicar na desorganização do ritmo dos elementos microclimáticos, que por sua vez poderá acarretar problemas ambientais diversos.

\section{REFERÊNCIAS}

ALVARENGA, Silvia Maria; BRASIL, Antonia Eloísa; DEL'ARCO, Diana Melo. Geomorfologia. In. Projeto RADAMBRASIL. Levantamento de recursos naturais. Folha SF 21 Campo Grande: Rio de Janeiro, 1982.

ARAUJO, Kallianna Dantas; Diferenciação microclimática em paisagens com

Diferentes formas de cobertura vegetal: o caso do Campus I da UFPB.João Pessoa,2002.

BERTRAND, G. Paisagem e Geografia Física Global: Esboço metodológico. Caderno de Ciências da Terra, 13. Inst. de Geografia-USP. São Paulo. 1971.

FLORENZANO, T.G. Iniciação em sensoriamento remoto. $3^{a}$ Ed de imagens de satélite para estudos ambientais. São Paulo: Oficina de Textos, 2011.

GODOI FILHO, J. D., Aspectos Geológicos do Pantanal Mato-grossense e sua Área de Influência. In: Simpósio Sobre Recursos Naturais e Sócio-Econômico do Pantanal, 1. 1986, Corumbá - MS. Anais... Brasília - DF. EMBRAPA/CPAP, 1986. p 63-77. 
MONTEIRO, C. A. F. O estudo geográfico do clima. Cadernos

Geográficos. n.1 (maio 1999). Florianópolis: Imprensa Universitária, 1999.

MONTEIRO, C. A. F. Geossistemas: a história de uma procura. São Paulo: Contexto, 2000.

GRADELLA, Frederico dos Santos. Comportamento térmico em unidades da Paisagem no Pantanal da Nhecolândia/MS-Brasil: estudo de caso na Fazenda Nhumirim/EMBRAPA/Pantanal. UFMS: Três Lagoas, 2005.

GRADELLA, dos S. F. Aspectos da Dinâmica Hidroclimática da Lagoa Salina do Meio na Fazenda Nhumirim e seu entorno, Pantanal da Nhecolândia, MS - Brasil. Dissertação (mestrado), UFMS/CPAQ, Aquidauana, 2008.

REZENDE FILHO, A. T. Variabilidade de salinidade de uma área em uma baía/vazante na Fazenda Nhumirim, Pantanal da Nhecolândia: estudo de um método cartográfico. (Especialização). UFMS/CPTL, Três Lagoas, 2003

ROSS, J. L. S. O registro cartográfico dos fatos geomórficos e a questão da taxionomia do relevo.Revista do Departamento de Geografia da USP. São Paulo: n. 6. 1992. 17-29p.

SAKAMOTO, Arnaldo Yoso; QUEIROZ NETO, José Pereira de; FERNANDES, Ermínio; LUCATTI, Hebert M. Topografia de lagoas salinas e seus entorno no Pantanal da Nhecolândia/MS. In: Resumos do II Simpósio Sobre Recursos Naturais e Sócio Econômicos do Pantanal: Manejo e Conservação. EMBRAPA/CPAP-UFMS: Corumbá, 1996.

SILVA, J.S.V. \& ABDON, M.M. 1998. Delimitação do Pantanal Brasileiro e suas subregiões. Pesquisa Agropecuária Brasileira 33:1703-1711 
SILVA, Lenise Robles Borba. Microclima no Pantanal Sul-mato-grossense: análise do campo térmico em unidades da Paisagem da Nhecolândia (monografia de graduação). UFMS/CPTL. Três Lagoas, 2003.

SILVA, M. H. S, Subsídios para a compreensão dos processos pedogenéticos da lagoa Salitrada: Pantanal da Nhecolândia, MS. Dissertação (mestrado), UFMS/CPAQ, Aquidauana, 2007. 